\title{
Volker Röben
}

\section{Außenverfassungsrecht}

\author{
Eine Untersuchung zur auswärtigen Gewalt des offenen Staates
}

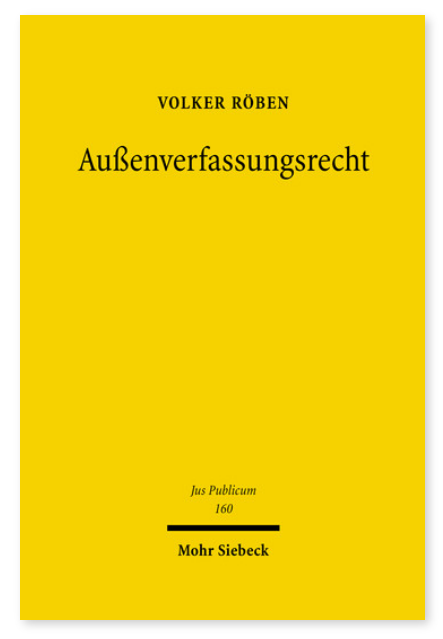

2007. XXIX, 570 Seiten. JusPubl 160

ISBN 978-3-16-151241-4

DOI 10.1628/978-3-16-151241-4

eBook PDF 149,00€

ISBN 978-3-16-149375-1

Leinen $149,00 €$
Ziel der Untersuchung ist, ein angemessenes Verständnis staatlicher Rechtsetzung in auswärtigen Gegenständen mit Wirkung nach außen und nach innen zu erlangen. Auf diese Rechtsetzung erheben Völkerrecht und nationales Verfassungsrecht einen Regelungsanspruch. Auswärtige Rechtsetzung ist daher als Gegenstand des Völkerrechts und des Verfassungsrechts zu betrachten. Die auswärtige Gewalt des vom Grundgesetz verfaßten Staates ist mithin öffentliche Gewalt eines Verfassungsstaates im vollen Sinne, also gesetzgebend, vollziehend und rechtsprechend, mit Wirkung nach außen und nach innen. Das kann mit dem Begriff des Außenverfassungsrechts erfaßt werden. Die Verfassung stellt neben den innerstaatlichen einen auswärtigen (völkerrechtlichen) Rechtsetzungsprozeß. Beide unterliegen konsistenter Verfassungsbindung. Die Untersuchung gliedert sich in sieben Teile. Zunächst stellt Volker Röben die Rechtsetzung im differenzierten Völkerrecht dar, um die eine Seite des normativen Rahmens auswärtiger Rechtsetzung zu beleuchten. Anschließend zeigt er die andere, verfassungsrechtliche Seite dieses Rahmens und prüft, wie das Grundgesetz diese Rechtsetzung rezipiert, sie innerstaatlichen Entscheidungsverfahren unterwirft und ihren Vollzug organisiert. Die drei Untersuchungsteile ergeben ein allgemeines Modell der auswärtigen Rechtsetzung als Problem des Völkerrechts und des Verfassungsrechts. Danach erprobt und vertieft Volker Röben dieses Modell an drei Referenzsystemen. Die Referenzsysteme sind die kollektive Sicherheit, die europäische Integration und der Grundrechtsschutz. Anhand jedes Bereichs kann eine zentrale dogmatische Frage des Außenverfassungsrechts demonstriert werden.

Volker Röben Geboren 1965; Studium der Rechtswissenschaften in Kiel, Genf und Surrey; 1998 Promotion; 2006 Habilitation; ab Juli 2007 Professor für Völkerrecht an der University of Swansea Wales, UK.

Jetzt bestellen:

https://mohrsiebeck.com/buch/aussenverfassungsrecht-9783161512414?no_cache=1

order@mohrsiebeck.com

Telefon: +49 (0)7071-923-17

Telefax: $+49(0) 7071-51104$ 